\title{
Identification of key candidate genes in local dorsal root ganglion inflammation by integrated bioinformatics analysis
}

\author{
LINHAI CHEN $^{1}$, JUNSHUI ZHENG $^{2}$, ZHUAN YANG $^{2}$, WEIWEI CHEN ${ }^{1}$, YANGJIAN WANG $^{1}$ and PENG WEI ${ }^{1}$ \\ ${ }^{1}$ Department of Plastic and Reconstructive Surgery, Ningbo First Hospital, Ningbo Hospital of Zhejiang University, \\ Ningbo, Zhejiang $315010 ;{ }^{2}$ Medical College, Ningbo University, Ningbo, Zhejiang 315211, P.R. China
}

Received July 25, 2020; Accepted March 18, 2021

DOI: $10.3892 / \mathrm{etm} .2021 .10253$

\begin{abstract}
The purpose of the present study was to identify potential markers of local dorsal root ganglion (DRG) inflammation to aid diagnosis, treatment and prognosis evaluation of DRG pain. A localized inflammation of the DRG (LID) rat model was used to study the contribution of inflammation to pain. The dataset GSE38859 was obtained from the Gene Expression Omnibus database. Pre-treatment standardization of gene expression data for each experiment was performed using the R/Bioconductor Limma package. Differentially expressed genes (DEGs) were identified between a LID model and a sham surgery control group. Gene Ontology (GO) and Kyoto Encyclopedia of Genes and Genomes (KEGG) pathway analyses of DEGs and gene set enrichment analysis (GSEA) were carried out using the 'clusterProfiler' package in R. Using the Search Tool for Retrieval of Interacting Genes, a protein-protein interaction network was constructed and visualized. Candidate genes with the highest potential validity were validated using reverse transcription-quantitative PCR and western blotting. In total, 66 DEGs were enriched in GO terms related to inflammation and the immune response processes. KEGG analysis revealed 14 associated signaling pathway terms. Protein-protein interaction network analysis revealed 9 node genes, 3 of which were among the top 10 DEGs. Matrix metallopeptidase 9, chemokine CXCL9, and complement component 3 were identified as key regulators of DRG inflammatory pain progression.
\end{abstract}

\section{Introduction}

Animal chronic pain models are usually classified as peripheral nerve injury models or inflammatory pain models (1). Both nerve injury and inflammation can produce spontaneous pain, hyperalgesia and abnormal pain, and both

Correspondence to: Professor Peng Wei, Department of Plastic and Reconstructive Surgery, Ningbo First Hospital, Ningbo Hospital of Zhejiang University, 59 Liuting Road, Ningbo, Zhejiang 315010, P.R. China

E-mail: dr_weipeng@163.com

Key words: bioinformatics, dorsal root ganglion, pain, gene expression profiles, differentially expressed genes can affect spontaneous discharges from the dorsal root ganglia (DRG) $(2,3)$. However, the potential mechanisms of DRG discharge differ between nerve injury and chronic inflammation. Nerve injury typically leads to overall downregulation of sodium channels and altered homotype expression (4). By contrast, chronic peripheral inflammation generally leads to the upregulation of tetrodotoxin-resistant sodium channels (5). Inflammation is a factor in most pain models, including those based on nerve injury (6). Macrophage infiltration, local pro-inflammatory cytokine release (7), DRG glial cell activation and retrograde transport to DRG are important triggers of hyperalgesia (8). Inflammation also occurs under clinical pain conditions, including postherpetic neuralgia and back pain after lumbar disc herniation $(9,10)$; the substance released from the nucleus pulposus is immunogenic, causing inflammation in adjacent DRGs. To learn more concerning the contribution of inflammation to pathological pain, Wang et al (11) developed the localized inflammation of the DRG (LID) model. In this model the cell bodies of sensory neurons are directly stimulated by the immune activator zymosan, without nerve injury. Considering the association between inflammatory processes and states of inflammatory and neuropathic chronic pain, the present study aimed to explore gene activity and expression changes induced by local inflammation of DRG.

Strong et al (12) submitted the GSE38859 dataset to the Gene Expression Omnibus (GEO) database. They screened behavior-related gene expression changes after DRG inflammation and demonstrated that immune-related genes were the largest category altered, including members of the complement system and several upregulated chemokine ligands, such as C-X-C motif ligand (CXCL)9, CXCL10 and CXCL16 (12). However, their study only focused on gene function and the role of numerous differentially expressed genes (DEGs) was not explored further. In the present study, in order to identify the key candidate genes and pathway changes in DRG inflammation various bioinformatics technologies were used to reanalyze the microarray data in the GEO database. CXCL9, complement component 3 (C3), and matrix metallopeptidase 9 (MMP9) were found to have strong interactive relationships with other genes, suggesting that they may be potential targets for the treatment of DRG inflammation-induced pain. These findings may provide greater insight into the genetic mechanisms underlying DRG inflammation pain and present potential therapeutic targets for the treatment of lower back pain. 


\section{Materials and methods}

Microarray data set collection and identification of DEGs. The microarray expression dataset GSE38859 was obtained from the Gene Expression Omnibus (https://www.ncbi.nlm.nih. gov/geo/). Exon expression profiling was based on the Agilent GPL6543 platform (Affymetrix Rat Exon 1.0 ST Array) and provided 6 sham and 6 inflamed DRG tissues. The probes were converted to the corresponding gene symbols according to the annotation information in the raw data. To reduce multiple testing, each corresponded to a unique gene symbol and only the probe set with the highest average expression was considered when multiple probe sets were associated with the same gene. Pre-treatment standardization on gene expression data for each experiment was performed using the R/Bioconductor Limma package. $R$ is the language and operating environment for statistical analysis and drawing. DEGs were uploaded to omicstudio (https://www.omicstudio.cn/tool?order=complex), a visual analytics platform for principal component analysis. After linear model fitting, the Bayesian linear model of the limma package was estimated to identify DEGs. Statistically significant DEGs were defined with $\mathrm{P}<0.05$ and $\mid \log \mathrm{FCl}>1$ as a cut-off criterion. Heatmap and volcano plots visualizations were performed using the R packages 'pheatmap' and 'ggplot2', respectively.

Enrichment analyses of DEGs. In the present study, Gene Ontology (GO) enrichment and Kyoto Encyclopedia of Genes and Genomes (KEGG) pathway analysis of DEGs were carried out using the $\mathrm{R}$ package. $\mathrm{P}<0.01$ was chosen as the cutoff criteria. Gene Set Enrichment Analysis (GSEA) was also performed using the 'clusterProfiler' package in R (13), and all visualization was handled in $\mathrm{R}$ using the ggplot2 graphics package. The whole gene expression values of the samples were analyzed based on the h.all.v 7.0.entrez.gmt [Hallmarks] gene set database (https://www.gsea-msigdb. org $/ \mathrm{gsea} / \mathrm{msigdb} /$ collections.jsp\#H). Significant enrichment pathways were defined by FDR $<0.25$ and $\mathrm{P}<0.05$.

Module screening from the protein-protein interaction (PPI) network. Comprehensive information on the proteins was identified and the Search Tool for Retrieval of Interacting Genes (STRING; v11.0; https://string-db.org/), a search tool for retrieving interacting genes/proteins, was used to evaluate protein-PPI information. Interaction between proteins within a cell facilitates our understanding of how proteins operate in a coordinated manner in the cell (14). Subsequently, the PPI network was constructed and visualized by Cytoscape software (version 3.7.1; https://cytoscape.org/). Molecular Complex Detection (MCODE) analysis, an app in Cytoscape, was then used to select the most significant PPI network modules. The criteria for selection were as follows: MCODE score $>3$; degree cutoff, 2; node score cut-off, 0.2; and max depth, 100.

Animals and local inflammation of the DRG (LID) models. Adult male Sprague Dawley rats purchased from the Experimental Animal Center of Zhejiang Province were used in this study. Rats used for experiments were aged 6-8 weeks, weighed 250-350 $\mathrm{g}$ and were sex-matched. A total of 16 rats were used in this present study. A sample size of 8 rats was used per experiment to ensure repeatability. The animals were housed
Table I. Primer sequences used in the present study.

\begin{tabular}{ll}
\hline Gene & \multicolumn{1}{c}{ Sequence } \\
\hline CXCL9 & F: 5'-GACCCAGATTCAGCAAGGGT-3' \\
& R: 5'-CTTTGACTCCGGATGGTGGG-3' \\
MMP-9 & F: 5'-GGTGATTGACGACGCCTTTG-3' \\
& R: 5'-CTGGATGACGATGTCTGCGT-3' \\
C3 & F: 5'-GCGGTACTACCAGACCATCG-3' \\
& R: 5'-CTTCTGGCACGACCTTCAGT-3' \\
GAPDH & F: 5'-AAGGTCGGTGAACGGATT-3' \\
& R: 5'-TGAACTTGCCGTGGGTAGAG-3'
\end{tabular}

F, forward; R, reverse; CXCL9, C-X-C motif ligand 9; MMP9, matrix metallopeptidase 9; C3, complement component 3 .

in a temperature-controlled animal facility (room temperature, $25^{\circ} \mathrm{C}$; humidity, $40-60 \%$ ) on a $12 \mathrm{~h}$ light-dark cycle and food and water was freely available. All procedures were approved by the Animal Care and Use Committee of Ningbo University following the Guidelines for the Care and Use of Laboratory Animals from the National Institutes of Health (NIH) (15).

An intraperitoneal injection was used to anesthetize the selected animals with sodium pentobarbital $(50 \mathrm{mg} / \mathrm{kg})$, before a longitudinal incision was made in the middle of the $\mathrm{S} 1$ to L4 spine. The back skin and muscular fasciae were bluntly isolated, exposing the L5 intervertebral foramen. With the needle still inside, $10 \mu \mathrm{l}$ of the immune activator zymosan ( $2 \mathrm{mg} / \mathrm{ml}$ in incomplete Freund's adjuvant; Sigma-Aldrich; Merck KGaA) was slowly injected into the L5 intervertebral foramen, above the DRG. The needle remained in place for an additional $3 \mathrm{~min}$ after injection to avoid leakage. A control group, sham animals, experienced the same surgery process without the final step of injecting zymosan.

Reverse transcription-quantitative PCR (RT-qPCR). RT-qPCR analysis was performed as previously described (16). After 3 days following LID- or sham- surgery, rats were decapitated following an overdose of pentobarbital sodium $(150 \mathrm{mg} / \mathrm{kg})$. Freshly isolated DRG tissues were collected on ice and immersed in TRIzol ${ }^{\circledR}$ reagent (Invitrogen; Thermo Fisher Scientific, Inc.) and immediately stored at $-80^{\circ} \mathrm{C}$ until the time of RNA extraction. Complementary DNA (cDNA) was synthesized with the reverse transcription enzyme SuperScript II (Invitrogen; Thermo Fisher Scientific, Inc.) together with reverse transcription primers at $50^{\circ} \mathrm{C}$ for $15 \mathrm{~min}$ and $85^{\circ} \mathrm{C}$ for $5 \mathrm{sec}$. cDNA was then amplified using a HiFiScript cDNA Synthesis Kit (CoWin Biosciences) using an ABI Q5 RT-PCR System (Applied Biosystems; Thermo Fisher Scientific, Inc.). All primers were synthesized by BGI Genomics Co., Ltd. (Table I). The synthesized cDNA was used qPCR to determine the expression changes in corresponding genes. The reaction mixture was: $10 \mu \mathrm{l} 2 \mathrm{X}$ SYBR Premix Ex Taq TMII, $1 \mu \mathrm{l} 10 \mu \mathrm{M}$ forward primer, $1 \mu \mathrm{l} 10 \mu \mathrm{M}$ reverse primer, $7 \mu \mathrm{l}$ $\mathrm{ddH} 2 \mathrm{O}$ and $1 \mu \mathrm{l} \mathrm{cDNA}$, in a total volume of $20 \mu \mathrm{l}$. The thermocycling conditions were: $95^{\circ} \mathrm{C}$ for $2 \mathrm{~min}$, followed by 40 cycles of $95^{\circ} \mathrm{C}$ for $10 \mathrm{sec}, 60^{\circ} \mathrm{C}$ for $50 \mathrm{sec}$. GAPDH or Actin were used as internal reference genes, and the relative expression changes in target genes were calculated by the $2^{-\Delta \Delta C q}$ method (17). 

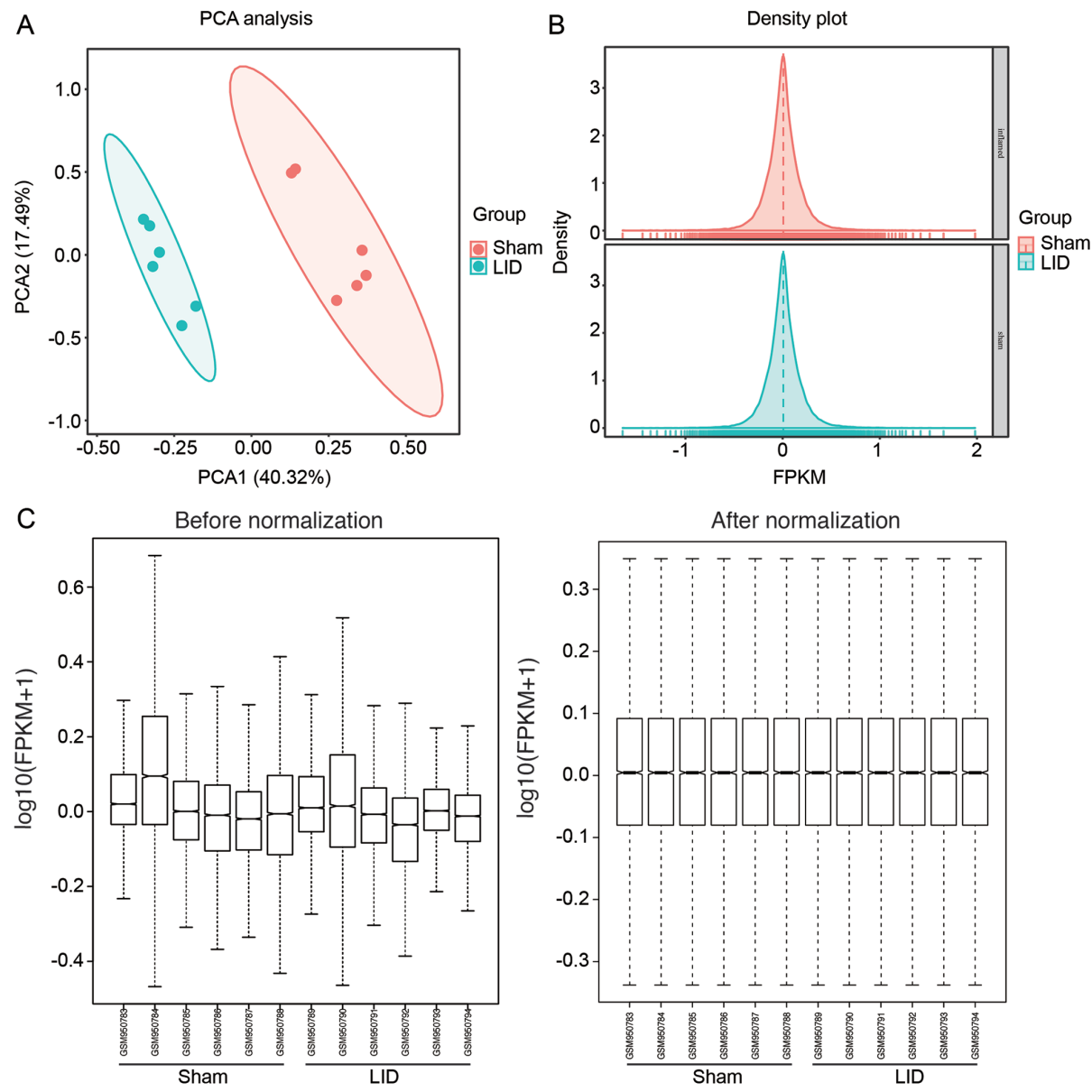

Figure 1. Distribution features of gene expression after normalization of all samples in GSE38859. (A) PCA. The red dots represent the sham group and the blue dots represent the LID group. Variances represented by PCA, 17.49\%. (B) Density plots. The top represents the sham group and the bottom represents the LID group. (C) Box plot. The left represents before normalization and the right represents after normalization. PCA, principal component analysis; LID, localized inflammation of the dorsal root ganglion; FPKM, fragments per Kb of transcript per million mapped reads.

Western blotting. The fresh tissues of mice were lysed in precooled RIPA buffer (EMD Millipore), and then homogenized using an automatic rapid sample grinder. The tissue homogenate was transferred to a sterile centrifuge tube, centrifuged at $4^{\circ} \mathrm{C}$ and $10,000 \mathrm{x} \mathrm{g}$ for $10 \mathrm{~min}$, and the supernatant was transferred to a new centrifuge tube. The protein concentration was determined using the BCA method (Thermo Fisher Scientific, Inc.). Total protein (20-30 $\mu \mathrm{g})$ was separated via SDS-PAGE electrophoresis (concentrated gel, 5\%; separation gel, 10-12\%). After SDS-PAGE electrophoresis, the electrophoresis was carried out at a constant current of $200 \mathrm{~mA}$ for $2 \mathrm{~h}$. At the end of membrane transfer, the nitrocellulose membrane was rinsed with TBS-0.02\% Tween-20 (TBST) and sealed at room temperature for $1-2 \mathrm{~h}$ with blocking solution (TBST containing 3-5\% skimmed milk powder). Rabbit anti-C3 (cat. no. 97425; Cell Signaling Technology, Inc.; 1:1,000), mouse anti-actin (cat. no. 3700; Cell Signaling Technology, Inc.; 1:10,000), rabbit anti- MMP9 (cat. no. 13667; Cell Signaling Technology, Inc.; 1:1000) and mouse anti-CXCL9 (cat. no. 93556; Cell Signaling Technology, Inc.; 1:1,000) were diluted with a primary antibody diluent [TBST solution containing 3\% BSA (Sigma-Aldrich; Merck KGaA) and 0.01\% sodium azide] and incubated at $4^{\circ} \mathrm{C}$ for $15-18 \mathrm{~h}$. Subsequently, the membranes were washed five times with TBST for 5 min each time. Horseradish peroxidase-conjugated secondary antibody (goat anti-mouse IgG: cat. no. E030110-01; EarthOx, LLC;
1:10,000; goat anti-rabbit IgG: cat. no. E030120-01; EarthOx, LLC; 1:10,000) was diluted in TBST solution and incubated at room temperature for $2 \mathrm{~h}$. Subsequently, TBST was used to rinse the membrane 5 times and TBS was used to rinse the membrane once, each time for $5 \mathrm{~min}$. After rinsing, SuperSignal ${ }^{\mathrm{TM}}$ West Atto Ultimate Sensitivity ECL substrate (cat. no. A38555; Thermo Fisher Scientific, Inc.) was added and then incubated in the dark for 1-5 min, before exposure to the chemiluminescence imaging system. The protein expression detected via western blotting was quantified using ImageJ v1.8.0 (NIH).

Statistical analysis. Data are presented as the mean \pm SEM. Analyses were performed using Microsoft Excel (version 16.44; Microsoft Corporation). Student's t-test was used to analyze statistical differences. $\mathrm{P}<0.05$ was considered to indicate a statistically significant difference.

\section{Results}

Data normalization. The primary purpose of normalization was to eliminate technical and systematic variability from the data compared between different samples. After microarray data normalization, biological variability between different samples was assessed by plotting a principal component analysis graph (Fig. 1A). DRG-inflamed (n=6) and DRG-sham 

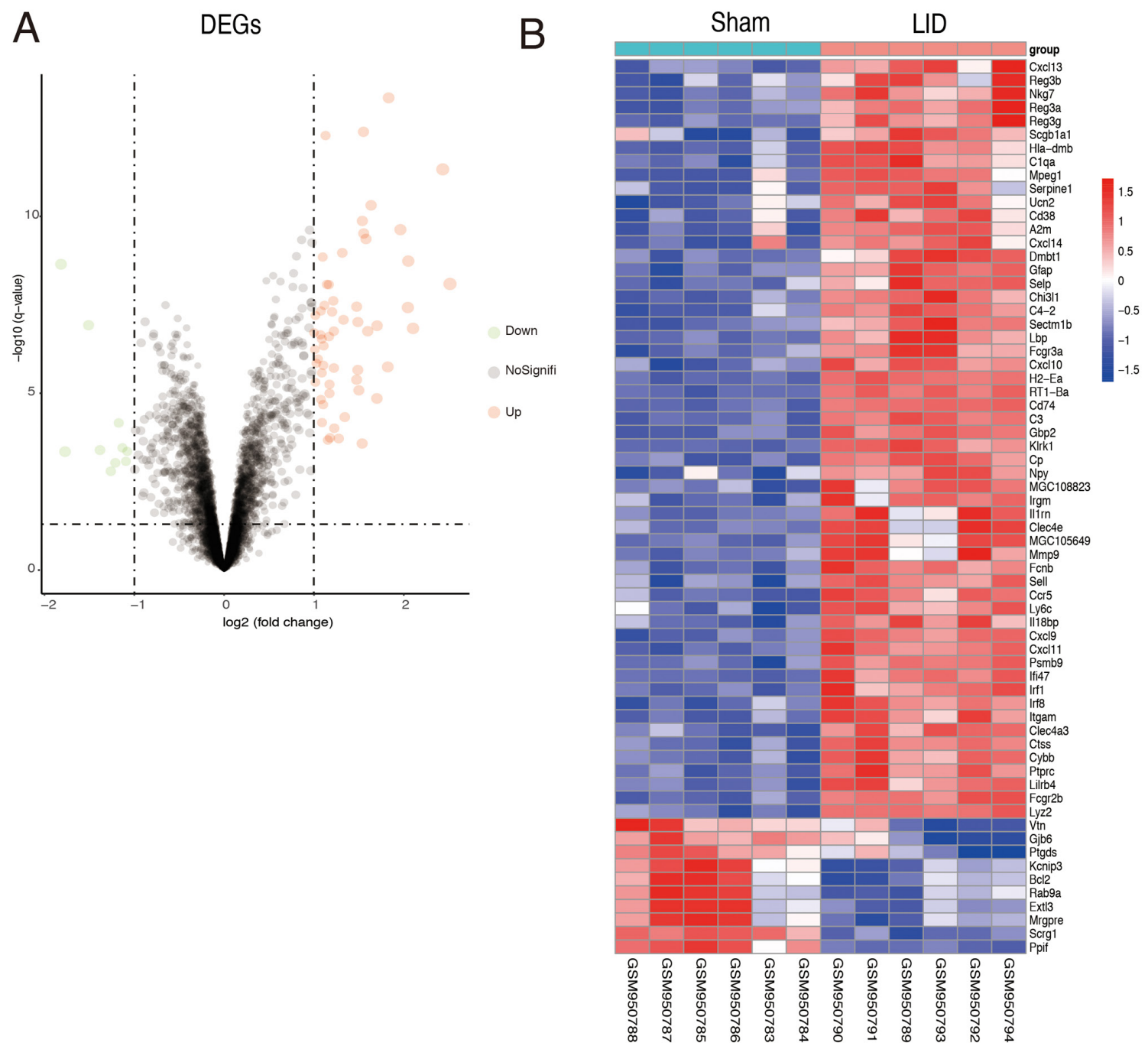

Figure 2. DEGs screened by GSE38859 were used for data analysis. (A) Volcano plot. The red dots represent upregulated genes and the green dots represent downregulated genes. (B) Heatmap. Blue indicates repressed mRNA levels and red elevated levels after LID surgery. DEGs, differentially expressed genes; LID, localized inflammation of the dorsal root ganglion.

$(n=6)$ overall had distinct, non-overlapping expression profiles. The density plot results demonstrated that the distribution of the sample intensities were generally consistent and could be used for downstream analysis (Fig. 1B). A box plot indicates each sample's gene expression and the black lines in the boxes were almost on the same straight line, indicating that the raw data were normalized successfully, which ensures the accuracy of the data (Fig. 1C).

Identification of DEGs. A total of 66 DEGs were screened, including 56 upregulated and 10 downregulated DEGs. In addition, the volcano plot of the DEGs is presented in Fig. 2A and heatmap plots in Fig. 2B.

Functional enrichment analysis of DRGs. To further investigate the function of DEGs, GO term and KEGG pathway analyses were displayed in R. DEGs were divided into three major functional categories, namely biological processes (BPs), molecular functions (MFs) and cellular components (CCs). Collectively, the data showed that DEGs were associated with GO terms related to immunity, including 'innate immune response', 'activation of immune response' and 'activation of inflammatory response' (Fig. 3A and Table II). In the MF category, DEGs were enriched in the terms 'carbohydrate binding', ' $\mathrm{G}$ protein-coupled receptor binding' and 'heparin binding' (Fig. 3A and Table III). In the $\mathrm{CC}$ analysis, the DEGs were enriched in the terms 'external side of plasma membrane', 'side of membrane' and 'rough endoplasmic reticulum' (Fig. 3A and Table IV). In these candidate DEGs, 14 signaling pathways were enriched in pathways in the KEGG database, including 'cytokine-cytokine receptor interaction', 'viral protein interaction with cytokine and cytokine receptor' and 'chemokine signaling pathway' pathways (Fig. 3B and Table V). In addition, GSEA was performed for all genes on the microarray. The results of GSEA suggested that the LID model expression profiles were enriched in genes associated with the terms 'interferon-gamma response' and 'inflammatory response' (Fig. 3C).

PPI network and module analysis. To investigate interaction between the DEGs, a PPI network was constructed in STRING, which consisted of 182 edges and 62 nodes. STRING analysis showed that a total of 54 genes were filtered into the DEG PPI network complex. The network was visualized using the 
A

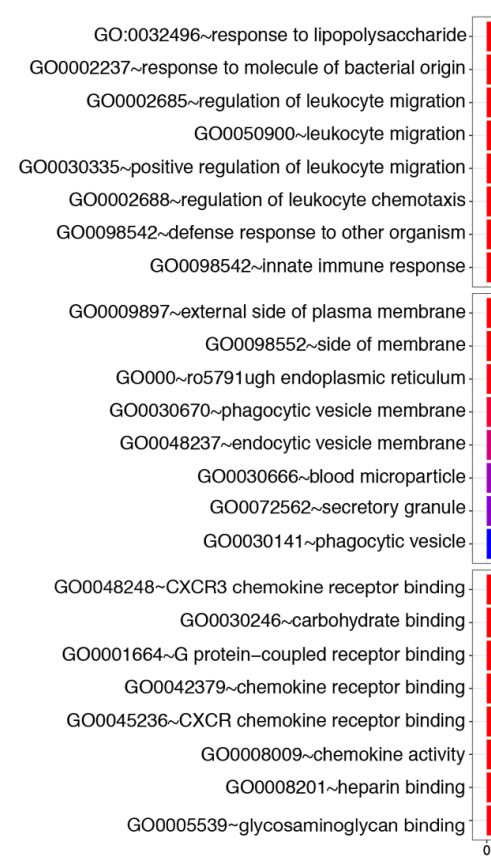

GO

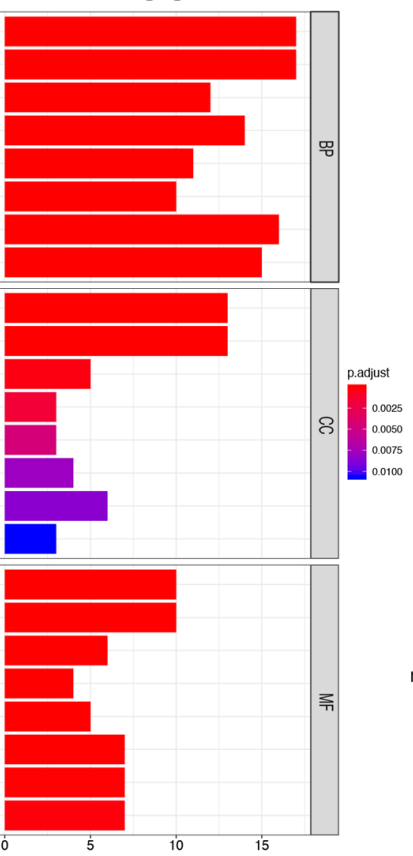

$\mathrm{B}$

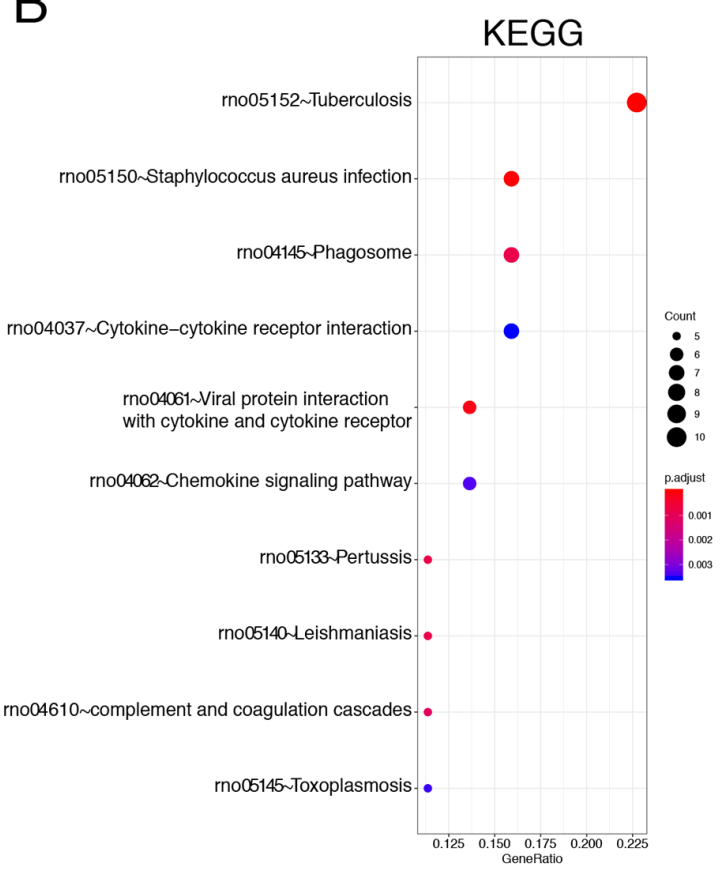

C
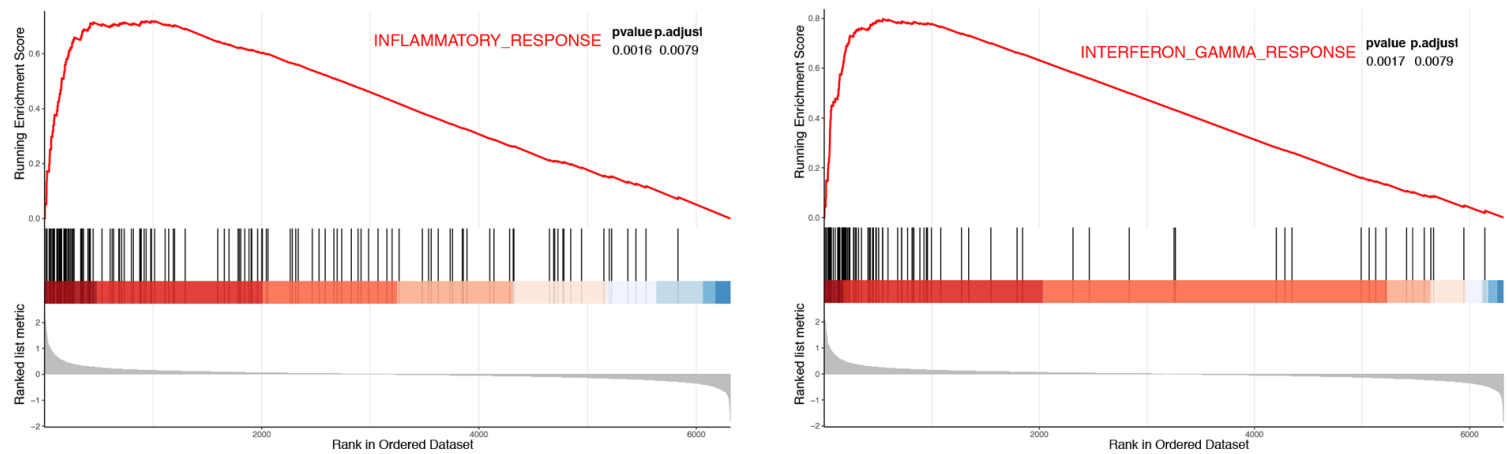

Figure 3. GO, KEGG and GSEA enrichment analysis of the DEGs were performed using ClusterProfiler. (A) GO analysis for LID models DEGs in the BP (top), CC (middle) and MF (bottom) categories. (B) KEGG pathways enrichment analysis of DEGs. (C) GSEA of a gene signature associated with the 'interferon gamma response' and the 'inflammatory response'. GO, Gene Ontology; KEGG, Kyoto Encyclopedia of Genes and Genomes; GSEA, Gene Set Enrichment Analysis; DEGs, differentially expressed genes; LID, localized inflammation of the dorsal root ganglion; BP, biological processes; CC, cellular component; MF, molecular function.

software tool Cytoscape (Fig. 4A). Moreover, three significant models were screened out from the PPI network by module analysis using MCODE in Cytoscape (Fig. 4A and Table VI). A total of 9 genes (MMP9, CXCL3, C3, Ptpre, CXCL11, CXCL9, CCr5, CXCL10 and C1qa) were screened out based on the high degree of connectivity ( $\geq 10$; Table VI). Furthermore, MMP9, CXCL3 and C3 overlapped within the top 10 DEGs. The sham DRG on the third day was compared with the LID DRG to verify the relevance of the screened genes via RT-qPCR. This time point was selected due to the frequent spontaneous activity of the DRG. Consistent with the bioinformatics results, the expression of MMP9, C3 and CXCL9 increased significantly after LID surgery (Fig. 4D).

\section{Discussion}

In the present study, 66 DEGs were screened from GSE38859 and used for further analyses in which potential targets were identified that may be useful for the treatment and diagnosis of LID. The DRG inflammation process must be more extensively understood in order to identify the most promising genes among a large list of candidate genes. The top 10 DEGs (H2-Ea, RT1-Ba, MMP9, C3, Gbp2, K1rk1, Fcgr2b, Ifi4, CXCL9 and Lyz2) were considered the most promising candidates likely to affect the DRG inflammation process. The PPI network showed interactions among the identified DEGs. The key nodes in the network may play critical roles in the pathological process of LID. In the PPI network, 9 DEGs (MMP9, CXCL3, C3, Ptprc, CXCL11, CXCL9, CCR5, CXCL10 and C1qa) were classified as hub genes, and 3 of these were among the top 10 DEGs (CXCL9, MMP9 and C3).

As localized inflammation of the L5 DRG induced a marked increase in spontaneous bursting activity, the material was sampled for RT-qPCR on the third day (18). The qPCR and western blotting results were consistent with the 
Table II. Top 20 GO biological process terms associated with differentially expressed genes.

\begin{tabular}{|c|c|c|c|c|}
\hline Term & Description & Genes & Counts & P-value \\
\hline GO:0032496 & $\begin{array}{l}\text { Response to } \\
\text { lipopolysaccharide }\end{array}$ & $\begin{array}{l}\text { Gbp2/K1rk1/Fcgr2b/Cxc19/ } \\
\text { Cxcl11/Ccr5/Lbp/Cxcl10/Irf8/Fcgr3a/ } \\
\text { Il18bp/Selp/I11rn/Serpine1/Mmp9/Scgb1a1/Gjb6 }\end{array}$ & 16 & $5.41 \times 10^{-15}$ \\
\hline GO:0002237 & $\begin{array}{l}\text { Response to molecule } \\
\text { of bacterial origin }\end{array}$ & $\begin{array}{l}\text { Gbp2/K1rk1/Fcgr2b/Cxc19/Cxcl11/ } \\
\text { Ccr5/Lbp/Cxcl10/Irf8/Fcgr3a/ } \\
\text { Il18bp/Selp/I11rn/Serpine1/Mmp9/Scgb1a1/Gjb6 }\end{array}$ & 16 & $1.03 \times 10^{-14}$ \\
\hline GO:0002685 & $\begin{array}{l}\text { Regulation of } \\
\text { leukocyte migration }\end{array}$ & $\begin{array}{l}\text { Cd74/Klrk1/Cxc19/Cxcl11/Lbp/Cxc110/Sell/Selp/ } \\
\text { Cxcl13/Serpine1/Mmp9/Cxcl14 }\end{array}$ & 12 & $4.72 \times 10^{-14}$ \\
\hline GO:0050900 & Leukocyte migration & $\begin{array}{l}\text { Cd74/Cxc19/Cxc111/Ptprc/Ccr5/Lbp/Cxcl10/Sell/ } \\
\text { Selp/Cxcl13/Serpine1/Mmp9/Cxcl14/Bcl2/Vtn }\end{array}$ & 16 & $4.81 \times 10^{-14}$ \\
\hline GO:0030335 & $\begin{array}{l}\text { Positive regulation of } \\
\text { cell migration }\end{array}$ & $\begin{array}{l}\text { Cd74/Cxc19/Cxcl11/Ptprc/Ccr5/Lbp/Cxcl10/Sell/Selp/ } \\
\text { Cxcl13/Serpine1/Mmp9/Cxcl14/Bcl2/Vtn }\end{array}$ & 15 & $7.88 \times 10^{-13}$ \\
\hline GO:0002688 & $\begin{array}{l}\text { Regulation of } \\
\text { leukocyte chemotaxis }\end{array}$ & $\begin{array}{l}\text { Cd74/Klrk1/Cxc19/Cxcl11/Lbp/Cxcl10/ } \\
\text { Sell/Cxcl13/Serpine1/Cxcl14 }\end{array}$ & 10 & $3.46 \times 10^{-13}$ \\
\hline GO:0098542 & $\begin{array}{l}\text { Defense response to } \\
\text { other organism }\end{array}$ & $\begin{array}{l}\text { Gbp2/Klrk1/Cxc19/Lyz2/Ptprc/Irf1/Ccr5/Lbp/Cxcl10/Irf8/ } \\
\text { Reg3g/Cxc113/Serpine1/Clec4e/Reg3b/Bcl2 }\end{array}$ & 16 & $6.33 \times 10^{-13}$ \\
\hline GO:0045087 & $\begin{array}{l}\text { Innate immune } \\
\text { response }\end{array}$ & $\begin{array}{l}\mathrm{RT} 1-\mathrm{Ba} / \mathrm{C} 3 / \mathrm{Gbp} 2 / \mathrm{Klrk} 1 / \mathrm{Fcnb} / \mathrm{Irf1} / \mathrm{Cybb} / \\
\mathrm{Lbp} / \mathrm{Reg} 3 \mathrm{~g} / \mathrm{C} 1 \mathrm{qa} / \mathrm{Irgm} / \mathrm{A} 2 \mathrm{~m} / \mathrm{Clec} 4 \mathrm{e}\end{array}$ & 13 & $2.01 \times 10^{-9}$ \\
\hline GO:2000147 & $\begin{array}{l}\text { Positive regulation of } \\
\text { cell motility }\end{array}$ & $\begin{array}{l}\text { Cd74/Cxc19/Cxc111/Ptprc/Ccr5/Lbp/Cxcl10/Sell/Selp/ } \\
\text { Cxcl13/Serpine1/Mmp9/Cxcl14/Bcl2/Vtn }\end{array}$ & 15 & $1.19 \times 10^{-12}$ \\
\hline GO:0051272 & $\begin{array}{l}\text { Positive regulation of } \\
\text { cellular component } \\
\text { movement }\end{array}$ & $\begin{array}{l}\text { Cd74/Cxc19/Cxcl11/Ptprc/Ccr5/Lbp/Cxcl10/Sell/ } \\
\text { Selp/Cxcl13/Serpine1/Mmp9/Cxcl14/Bcl2/Vtn }\end{array}$ & 15 & $1.65 \times 10^{-12}$ \\
\hline GO:0040017 & $\begin{array}{l}\text { Positive regulation of } \\
\text { locomotion }\end{array}$ & $\begin{array}{l}\text { Cd74/Cxc19/Cxcl11/Ptprc/Ccr5/Lbp/Cxcl10/Sell/ } \\
\text { Selp/Cxcl13/Serpine1/Mmp9/Cxcl14/Bcl2/Vtn }\end{array}$ & 15 & $2.44 \times 10^{-12}$ \\
\hline GO:0006935 & Chemotaxis & $\begin{array}{l}\text { Cd74/C3/Klrk1/Cxc19/Cxc111/Ccr5/Lbp/ } \\
\text { Cxcl10/Itgam/Sell/Cxc113/Serpine1/Cxcl14 }\end{array}$ & 13 & $1.31 \times 10^{-9}$ \\
\hline GO:0060326 & Cell chemotaxis & $\begin{array}{l}\text { Cd74/Klrk1/Cxc19/Cxcl11/Ccr5/Lbp/Cxcl10/ } \\
\text { Itgam/Sell/Cxcl13/Serpine1/Cxcl14 }\end{array}$ & 12 & $3.59 \times 10^{-12}$ \\
\hline GO:0030595 & Leukocyte chemotaxis & $\begin{array}{l}\text { Cd74/Klrk1/Cxc19/Cxcl11/Lbp/Cxcl10/ } \\
\text { Itgam/Sell/Cxc113/Serpine1/Cxcl14 }\end{array}$ & 11 & $2.76 \times 10^{-12}$ \\
\hline GO:0002253 & $\begin{array}{l}\text { Activation of } \\
\text { immune response }\end{array}$ & $\begin{array}{l}\text { C3/Klrk1/Fcnb/Ptprc/Irf1/Lbp/ } \\
\text { Reg3g/C1qa/A2m/Cd38/Bcl2 }\end{array}$ & 11 & $8.13 \times 10^{-10}$ \\
\hline GO:0002687 & $\begin{array}{l}\text { Positive regulation of } \\
\text { leukocyte migration }\end{array}$ & $\begin{array}{l}\text { Cd74/Cxc19/Cxc111/Lbp/Cxcl10/Sell/ } \\
\text { Selp/Cxc113/Serpine1/Mmp9/Cxcl14 }\end{array}$ & 11 & $7.89 \times 10^{-14}$ \\
\hline GO:0042742 & $\begin{array}{l}\text { Defense response } \\
\text { to bacterium }\end{array}$ & $\begin{array}{l}\text { Gbp2/Klrk1/Lyz2/Ccr5/Lbp/Irf8/Reg3g/ } \\
\text { Cxcl13/Serpine1/Clec4e/Reg3b }\end{array}$ & 11 & $5.31 \times 10^{-11}$ \\
\hline GO:0050921 & $\begin{array}{l}\text { Positive regulation } \\
\text { of chemotaxis }\end{array}$ & $\begin{array}{l}\text { Cd74/Cxc19/Cxc111/Ccr5/Lbp/Cxcl10/Sel1/ } \\
\text { Cxcl13/Serpine1/Cxcl14 }\end{array}$ & 10 & $5.20 \times 10^{-12}$ \\
\hline GO:0002526 & $\begin{array}{l}\text { Acute inflammatory } \\
\text { response }\end{array}$ & $\begin{array}{l}\text { C3/Fcgr2b/Ccr5/Lbp/Reg3a/ } \\
\text { Reg3g/A2m/Il1rn/Reg3b }\end{array}$ & 9 & $1.70 \times 10^{-10}$ \\
\hline GO:0006953 & Acute-phase response & Ccr5/Lbp/Reg3a/Reg3g/A2m/Il1rn/Reg3b & 7 & $1.30 \times 10^{-10}$ \\
\hline
\end{tabular}

GO, Gene Ontology.

bioinformatics results, showing that CXCL9, MMP9 and C3 were increased significantly in a LID model in comparison with a sham.
Chemokine-mediated neuroinflammation plays a critical role in neuropathic pain pathogenesis $(19,20)$. CXCL9, also known as monokine induced by interferon- $\gamma$, 


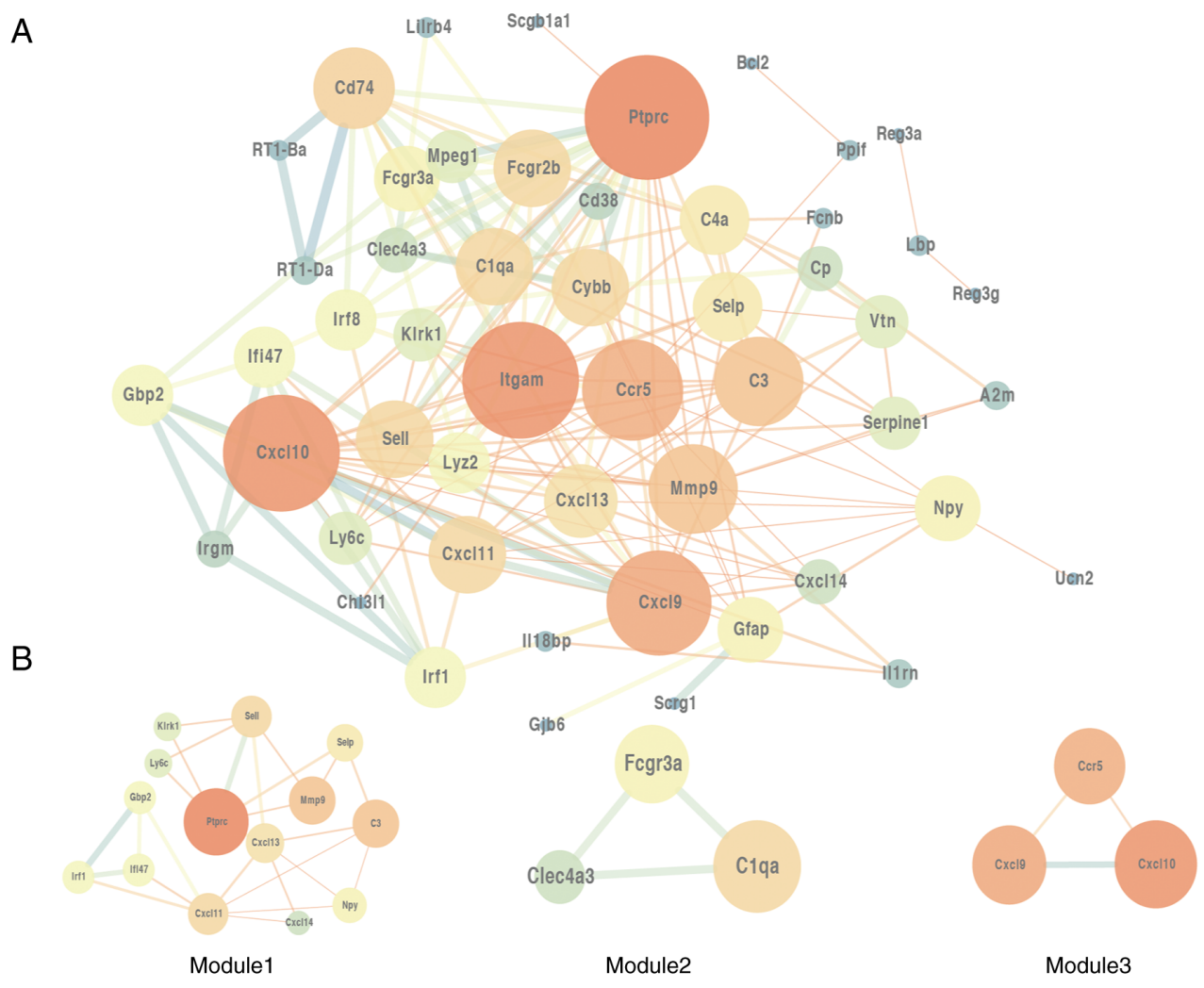

C
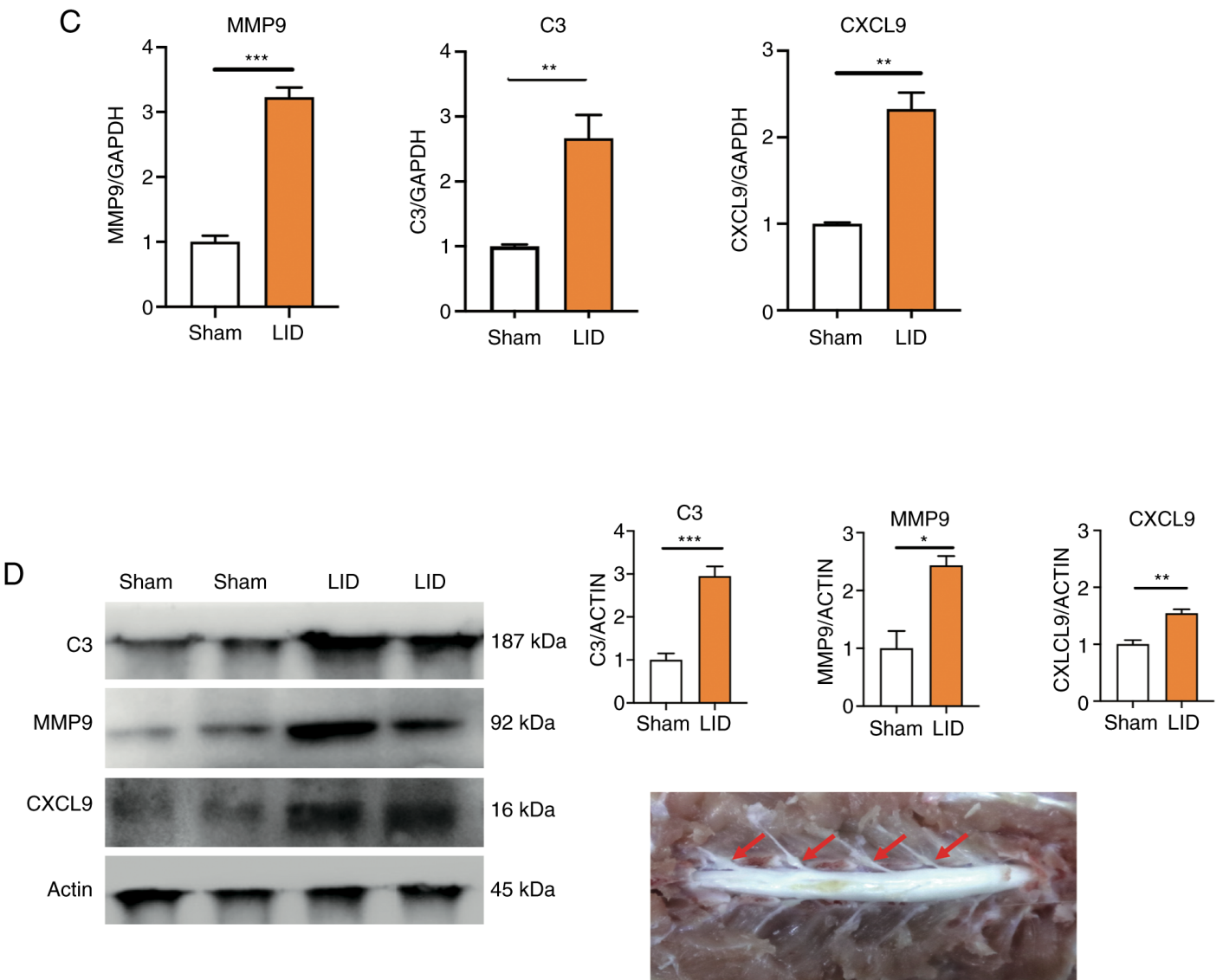

Figure 4. PPI network of DEGs. (A) PPI network of DEGs. (B) Identification of a sub-network. (C) Gene expression of CXCL9, MMP9, C3 in DRG tissue after surgery were validated by reverse transcription-quantitative PCR. (D) The level of DRG, C3, MMP9 and CX3CL9 protein after sham and LID surgery and isolated DRG tissues. ${ }^{*} \mathrm{P}<0.05,{ }^{* *} \mathrm{P}<0.01,{ }^{* * * *} \mathrm{P}<0.001$. PPI, protein-protein interaction; DEGs, differentially expressed genes; DRG, dorsal root ganglia; LID, localized inflammation of the dorsal root ganglion; CXCL9, C-X-C motif ligand 9; MMP9, matrix metallopeptidase 9; C3, complement component 3. 
Table III. Top 20 GO molecular function terms associated with differentially expressed genes.

\begin{tabular}{|c|c|c|c|c|}
\hline Term & Description & Genes & Counts & P-value \\
\hline GO:0048248 & $\begin{array}{l}\text { CXCR3 chemokine } \\
\text { receptor binding }\end{array}$ & Cxc19/Cxc111/Cxcl10/Cxcl13 & 4 & $6.27 \times 10^{-10}$ \\
\hline GO:0030246 & Carbohydrate binding & $\begin{array}{l}\text { Klrk1/Fcnb/Chi311/Reg3a/Reg3g/Sell/Selp/ } \\
\text { Clec4e/Reg3b/Vtn }\end{array}$ & 10 & $1.01 \times 10^{-8}$ \\
\hline GO:0001664 & $\begin{array}{l}\text { G protein-coupled } \\
\text { receptor binding }\end{array}$ & $\begin{array}{l}\text { C3/Cxc19/Cxc111/Fcnb/Ccr5/ } \\
\text { Cxc110/Cxcl13/Npy/Ucn2/Cxcl14 }\end{array}$ & 10 & $1.37 \times 10^{-8}$ \\
\hline GO:0042379 & Chemokine receptor binding & Cxc19/Cxcl11/Ccr5/Cxcl10/Cxcl13/Cxcl14 & 6 & $1.39 \times 10^{-8}$ \\
\hline GO:0045236 & CXCR chemokine receptor binding & Cxc19/Cxcl11/Cxcl10/Cxcl13 & 4 & $8.78 \times 10^{-8}$ \\
\hline GO:0008009 & Chemokine activity & Cxc19/Cxc111/Cxcl10/Cxcl13/Cxcl14 & 5 & $1.40 \times 1^{0-7}$ \\
\hline GO:0008201 & Heparin binding & Cxcl11/Ptprc/Cxcl10/Itgam/Selp/Cxcl13/Vtn & 7 & $3.29 \times 10^{-7}$ \\
\hline GO:0005539 & Glycosaminoglycan binding & Cxcl11/Ptprc/Cxcl10/Itgam/Selp/Cxc113/Vtn & 7 & $1.96 \times 10^{-6}$ \\
\hline GO:1901681 & Sulfur compound binding & Cxcl11/Ptprc/Cxcl10/Itgam/Selp/Cxcl13/Vtn & 7 & $1.08 \times 10^{-8}$ \\
\hline GO:0019955 & Cytokine binding & $\mathrm{Cd} 74 / \mathrm{Ccr} 5 / \mathrm{Il} 18 \mathrm{bp} / \mathrm{A} 2 \mathrm{~m} / \mathrm{I} 11 \mathrm{rn}$ & 5 & $1.13 \times 10^{-8}$ \\
\hline GO:0005126 & Cytokine receptor binding & Cxc19/Cxcl11/Ccr5/Cxcl10/Cxcl13/I11rn/Cxcl14 & 7 & $2.21 \times 10^{-5}$ \\
\hline GO:0022804 & Transmembrane transporter activity & Ctss/Ptprc/Ccr5/Itgam/Selp & 5 & $3.42 \times 10^{-5}$ \\
\hline GO:0005125 & Cytokine activity & Cxc19/Cxcl11/Cxcl10/Cxcl13/I11rn/Cxcl14 & 6 & $3.80 \times 10^{-5}$ \\
\hline GO:0043394 & Proteoglycan binding & Ctss/Ptprc/Itgam & 3 & $1.47 \times 10^{-4}$ \\
\hline GO:0019966 & Interleukin-1 binding & $\mathrm{A} 2 \mathrm{~m} / \mathrm{Il} 1 \mathrm{rn}$ & 2 & $1.73 \times 10^{-4}$ \\
\hline GO:0033691 & Sialic acid binding & Fcnb/Selp & 2 & $2.41 \times 10^{-4}$ \\
\hline GO:0019864 & IgG binding & Fcgr2b/Fcgr3a & 2 & $6.27 \times 10^{-4}$ \\
\hline GO:0002020 & Protease binding & Sell/A2m/Serpine $1 / \mathrm{Bcl} 2$ & 4 & $6.98 \times 10^{-4}$ \\
\hline GO:0042165 & Neurotransmitter binding & Chrna2/Chat/Chrna1/Slc6a12 & 4 & $7.87 \times 10^{-4}$ \\
\hline GO:0015294 & Solute: cation symporter activity & Slc45a3/Slc28a1/Slc13a3/Slc13a4/Slc6a12 & 5 & $8.38 \times 10^{-4}$ \\
\hline
\end{tabular}

GO, Gene Ontology.

is a CXC family chemokine (21). CXCL9 is produced by interferon- $\gamma$-stimulated macrophages and glial cells (22). A recent article reported that CXCL9 is primarily expressed in calcitonin gene-related peptide-positive and isolectin B4-positive DRG neurons and participates in the development of cancer-induced pain (23). However, a different study noted that spinal CXCL9 does not contribute to neuropathic pain despite its upregulation in the spinal cord after spinal nerve injury (24). This suggests that the mechanism of neuropathic pain differs from pain models and that CXCL9 has different functions in different tissues and distinct tissue specificity. CXCL9 was identified as a seed gene in the present PPI analysis. Seed gene are most closely related to disease genes, and these genes may become new disease-related targets. In light of these observations, it was concluded that CXCL9 may be a good candidate biomarker for diagnosing DRG inflammation.

Kawasaki et al (25) found increased MMP9 levels shortly after nerve injury in injured DRG primary sensory neurons. Moreover, treatment with an MMP9 inhibitor delayed allodynia and hyperalgesia for 11 days $(26,27)$, implying that MMP9 participates in the onset rather than the maintenance of neuropathic pain. Liou et al (26) used a spinal nerve ligation (SNL) model to demonstrate that MMP9 concentrations were upregulated after nerve injury and then returned to the normal ranges within 14 days.
MMP9 is significantly associated with the onset of neuropathic pain rather than its maintenance (28). However, specific molecular mechanisms related to MMP9 and DRG inflammation pain are lacking; this mechanism should be further investigated, as MMP9 may be a novel candidate biomarker for DRG inflammation pain.

Complement is a key component of the innate immune system, and mounting evidence suggests that ongoing complement activation may lead to pain after inflammation and injury (29). C5a and C3a can activate and sensitize skin nociceptors (30). C3 knockout rats have reduced intradermal nerve fiber density after paclitaxel treatment and reduced mechanical allodynia (31). However, the role of complement in LID remains unclear. C3 may be a potential candidate biomarker for LID.

GO and KEGG analyses of the DEGs were performed to further understand the molecular basis for DRG inflammatory pain mechanisms. GO BPs were mainly enriched in inflammation and immunity terms, including 'response to lipopolysaccharide', 'response to molecule of bacterial origin' and 'acute inflammatory response'. KEGG pathway enrichment analysis suggested that these DEGs were related to the terms 'chemokine signaling pathway' and 'cytokine-cytokine receptor interactions'.

Neuropathic pain can cause central sensitization $(32,33)$, and its mechanisms include cytokine and chemokine release 
Table IV. Top 20 GO cellular components terms associated with differentially expressed genes.

\begin{tabular}{|c|c|c|c|c|}
\hline Term & Description & Genes & Counts & P-value \\
\hline GO:0009897 & $\begin{array}{l}\text { External side of } \\
\text { plasma membrane }\end{array}$ & $\begin{array}{l}\text { RT1-Ba/Cd74/Klrk1/Fcgr2b/Cxc19/Fcnb/ } \\
\text { Ptprc/Ccr5/Cxcl10/Itgam/Fcgr3a/Sell/Selp }\end{array}$ & 13 & $4.42 \times 10^{-4}$ \\
\hline GO:0098552 & Side of membrane & $\begin{array}{l}\text { RT1-Ba/Cd74/Klrk1/Fcgr2b/Cxc19/Fcnb/Ptprc/ } \\
\text { Ccr5/Cxc110/Itgam/Fcgr3a/Sell/Selp }\end{array}$ & 6 & $5.88 \times 10^{-4}$ \\
\hline GO:0005791 & Rough endoplasmic reticulum & Lyz2/Cybb/Scgb1a1/Vtn/Ptgds & 5 & $7.82 \times 10^{-4}$ \\
\hline GO:0030670 & Phagocytic vesicle membrane & Dmbt1/Irgm/Rab9a & 3 & $1.13 \times 10^{-3}$ \\
\hline GO:0048237 & $\begin{array}{l}\text { Rough endoplasmic } \\
\text { reticulum lumen }\end{array}$ & Lyz2/Vtn & 2 & $1.17 \times 10^{-3}$ \\
\hline GO:0030666 & Endocytic vesicle membrane & Dmbt1/Irgm/Rab9a & 3 & $1.17 \times 10^{-3}$ \\
\hline GO:0072562 & Blood microparticle & $\mathrm{C} 3 / \mathrm{Cp} / \mathrm{A} 2 \mathrm{~m} / \mathrm{Vtn}$ & 3 & $1.17 \times 10^{-3}$ \\
\hline GO:0030141 & Secretory granule & Lyz2/Selp/Dmbt1/Serpine1/Reg3b/Scgb1a1 & 6 & $1.78 \times 10^{-3}$ \\
\hline GO:0062023 & $\begin{array}{l}\text { Collagen-containing } \\
\text { extracellular matrix }\end{array}$ & $\begin{array}{l}\text { Igf1/Elane/Srpx2/Lox11/Colec12/Igfbp6/Co19a2/ } \\
\text { Omd/Lamc2/Adamts2/Col8a2 }\end{array}$ & 11 & $2.11 \times 10^{-3}$ \\
\hline GO:0030016 & Myofibril & Myo18b/Rp14/Nrap/Tnnt2/Myh2/Ryr1/Capn3/Tnnc2 & 8 & $2.33 \times 10^{-3}$ \\
\hline GO:0005861 & Troponin complex & Tnnt2/Tnnc2 & 2 & $3.19 \times 10^{-3}$ \\
\hline GO:0043292 & Contractile fiber & Myo18b/Rp14/Nrap/Tnnt2/Myh2/Ryr1/Capn3/Tnnc2 & 8 & $3.45 \times 10^{-3}$ \\
\hline GO:0070382 & Exocytic vesicle & Hspa8/Igf1/Syt10/Sept1/Cplx3/Sphk1/Sytl1/Wfs1 & 8 & $5.87 \times 10^{-3}$ \\
\hline GO:0002177 & Manchette & Spef2/Iqcg & 2 & $6.14 \times 10^{-3}$ \\
\hline GO:0043198 & Dendritic shaft & Hspa8/Hcn1/Rgs7bp/Ntsr1 & 4 & $6.25 \times 10^{-3}$ \\
\hline GO:0098684 & Photoreceptor ribbon synapse & Hspa8/Cplx3 & 2 & $7.32 \times 10^{-3}$ \\
\hline GO:0099026 & $\begin{array}{l}\text { Anchored component of } \\
\text { presynaptic membrane }\end{array}$ & Rgs 7bp/Cplx3 & 2 & $7.32 \times 10^{-3}$ \\
\hline GO:0001772 & Immunological synapse & Cd3e/Rhoh/Zap70 & 3 & $8.22 \times 10^{-3}$ \\
\hline GO:0030133 & Transport vesicle & $\begin{array}{l}\text { Hspa8/Igf1/Syt10/Sept1/Lyz1/Cplx3/ } \\
\text { Sphk1/Syt11/Wfs1 }\end{array}$ & 9 & $9.49 \times 10^{-3}$ \\
\hline GO:0042101 & $\mathrm{T}$ cell receptor complex & Cd3e/Zap70 & 2 & $1.14 \times 10^{-3}$ \\
\hline
\end{tabular}

GO, Gene Ontology.

Table V. KEGG pathway analysis.

\begin{tabular}{|c|c|c|c|c|}
\hline ID & Description & Genes & Counts & P-value \\
\hline rno05152 & Tuberculosis & $\begin{array}{l}\text { RT1-Ba/Cd74/C3/Fcgr2b/Ctss/Lbp/Itgam/ } \\
\text { Fcgr3a/Clec4e/Bcl2 }\end{array}$ & 10 & $1.56 \times 10^{-8}$ \\
\hline rno05150 & $\begin{array}{l}\text { Staphylococcus } \\
\text { aureus infection }\end{array}$ & RT1-Ba/C3/Fcgr2b/Itgam/Fcgr3a/Selp/C1qa & 7 & $6.21 \times 10^{-7}$ \\
\hline ron04145 & Phagosome & RT1-Ba/C3/Fcgr2b/Itgam/Fcgr3a/Ctss/Cybb & 7 & $3.44 \times 10^{-6}$ \\
\hline rno04060 & $\begin{array}{l}\text { Cytokine-cytokine } \\
\text { receptor interaction }\end{array}$ & Cxc19/Cxcl11/Ccr5/Cxcl10/Cxcl13/I11rn/Cxcl14 & 7 & $2.82 \times 10^{-5}$ \\
\hline rno04061 & $\begin{array}{l}\text { Viral protein interaction with } \\
\text { cytokine and cytokine receptor }\end{array}$ & Cxc19/Cxcl11/Ccr5/Cxc110/Cxcl13/ Cxcl14 & 6 & $3.65 \times 10^{-5}$ \\
\hline rno04062 & Chemokine signaling pathway & Cxc19/Cxcl11/Ccr5/Cxcl10/Cxcl13/ Cxcl14 & 6 & $4.14 \times 10^{-5}$ \\
\hline rno05133 & Pertussis & C3/Irf1/Irf8/Itgam/C1qa & 5 & $6.53 \times 10^{-5}$ \\
\hline rno05140 & Leishmaniasis & RT1-Ba/C3/Cybb/Itgam/Fcgr3a & 5 & $2.26 \times 10^{-4}$ \\
\hline rno04610 & $\begin{array}{l}\text { Complement and } \\
\text { coagulation cascades }\end{array}$ & C3/Itgam/C1qa/Serpine1/Vtn & 5 & $2.62 \times 10^{-4}$ \\
\hline rno05145 & Toxoplasmosis & RT1-Ba/Ccr5/Ppif/Irgm/Bcl2 & 5 & $3.00 \times 10^{-4}$ \\
\hline
\end{tabular}

KEGG, Kyoto Encyclopedia of Genes and Genomes. 
Table VI. Module analysis of differentially expressed genes using Cytoscape.

\begin{tabular}{llccc}
\hline Module & Gene & MCODE_Score & Degree & Topological coefficient \\
\hline Module1 & Ptprc & 5.2 & 23 & 0.386188069 \\
& Mmp9 & 6 & 14 & 0.671360536 \\
& C3 & 5.78 & 14 & 0.46776785 \\
& Sell & 5.2 & 11 & 0.594848482 \\
& Cxc111 & 5.78 & 11 & 0.576136362 \\
& Cxc113 & 5.06 & 10 & 0.629525 \\
& Selp & 5 & 9 & 0.630740735 \\
& Npy & 6 & 8 & 0.597535717 \\
& Ifi47 & 5 & 7 & 0.670634926 \\
& Irf1 & 5 & 7 & 0.670634926 \\
& Gbp2 & 5 & 7 & 0.62438424 \\
& Klrk1 & 6 & 6 & 0.868472224 \\
Ly6c & 6 & 6 & 0.868472224 \\
Cxc114 & 5 & 5 & 1.000 .999 .996 \\
CXdule2 & CCr5 & 4.3 & 18 & 1 \\
& CXCL10 & 4.08 & 17 & 1 \\
& Clec4a3 & 4.08 & 21 & 0.88148148 \\
& C1qa & 3.73 & 5 & 1 \\
& Fcgr3a & 3.88 & 11 & 0.74955445 \\
& & 3.42 & 8 & 0.69727273 \\
\hline
\end{tabular}

by spinal cord glial cells $(19,34,35)$. Increasing evidence indicates that chemokine signals are crucial players in neuropathic pain $(20,34,36-38)$. CXCL10 promotes neuropathic pain by increasing the permeability of the blood-spinal cord barrier (20). The activation of $\mathrm{C}-\mathrm{C}$ chemokine receptor type 5 reduces the analgesic function of opioid receptors and enhances pain at the inflammation site $(39,40)$.

The aforementioned findings are consistent with the KEGG analysis in the present study; however, these studies were based on spared nerve injury or SNL models. Therefore, the specific molecular mechanism of chemokines in DRG inflammation pain needs further study.

To verify the consistency of the GO and KEGG pathway enrichment analyses, GSEA analysis was performed on all genes. The analysis showed that the LID model was closely related to the terms 'inflammatory response', 'interferon- $\gamma$ response' and interferon- $\alpha$ response pathways, supporting the GO and KEGG analyses' results.

The molecular mechanisms of lower back pain caused by DRG inflammatory pain and nerve root pain may differ. The present study's main purpose was to identify candidate genes related to local DRG inflammation, providing potential targets for the treatment or monitoring of certain forms of lower back pain that are unrelated to mechanical oppression. Although the genes identified in the present study were initially confirmed in a previous study, further studies are needed to explore these genes and pathways' specific regulatory mechanisms.

In summary, 66 DEGs were subjected to extensive bioinformatics analyses and CXCL9, MMP9, and C3 were identified as the most promising biomarkers or therapeutic targets for DRG inflammation.

\section{Acknowledgements}

Not applicable.

\section{Funding}

This study was funded by a grant from the Medical and Health Science and Technology project of Zhejiang Province (grant no. 2019KY569).

\section{Availability of data and materials}

The datasets generated and/or analyzed during the current study are available in the Gene Expression Omnibus repository, https://www.ncbi.nlm.nih.gov/geo/query/acc.cgi?acc=GSE38859.

\section{Authors' contributions}

LC, JZ and ZY contributed to animal experiments, analysis and interpretation of the data and drafted the manuscript. LC, PW, WC and YW contributed to experiments, analysis and interpretation of the data and writing of the manuscript. PW supervised the study and contributed to the conception and design of the study, the analysis and interpretation of the data and writing of the manuscript. All authors read and approved the final version of the manuscript. LC and PW confirm the authenticity of all the raw data. All authors read and approved the final manuscript.

\section{Ethics approval and consent to participate}

All animal procedures were approved by the Animal Care and Use Committee of Ningbo University. 


\section{Patient consent for publication}

Not applicable.

\section{Competing interests}

The authors declare that they have no competing interests.

\section{References}

1. Burma NE, Leduc-Pessah H, Fan CY and Trang T: Animal models of chronic pain: Advances and challenges for clinical translation. J Neurosci Res 95: 1242-1256, 2017.

2. North RY,Li Y,Ray P,Rhines LD, Tatsui CE,Rao G,Johansson CA, Zhang H, Kim YH, Zhang B, et al: Electrophysiological and transcriptomic correlates of neuropathic pain in human dorsal root ganglion neurons. Brain 142: 1215-1226, 2019.

3. Chen G, Kim YH, Li H, Luo H, Liu DL, Zhang ZJ, Lay M, Chang W, Zhang YQ and Ji RR: PD-L1 inhibits acute and chronic pain by suppressing nociceptive neuron activity via PD-1. Nat Neurosci 20: 917-926, 2017.

4. Alles SRA and Smith PA: Etiology and pharmacology of neuropathic pain. Pharmacol Rev 70: 315-347, 2018.

5. Villarreal CF, Sachs D, Funez MI, Parada CA, de Queiroz Cunha F and Ferreira SH: The peripheral pro-nociceptive state induced by repetitive inflammatory stimuli involves continuous activation of protein kinase $\mathrm{A}$ and protein kinase $\mathrm{C}$ epsilon and its $\mathrm{Na}(\mathrm{V}) 1.8$ sodium channel functional regulation in the primary sensory neuron. Biochem Pharmacol 77: 867-877, 2009.

6. Sommer C, Leinders $M$ and Üçeyler N: Inflammation in the pathophysiology of neuropathic pain. Pain 159: 595-602, 2018.

7. Wang H, Xu H, Wu LJ, Kim SS, Chen T, Koga K, Descalzi G, Gong B, Vadakkan KI, Zhang X, et al: Identification of an adenylyl cyclase inhibitor for treating neuropathic and inflammatory pain. Sci Transl Med 3: 65ra3, 2011.

8. Todd AJ: Neuronal circuitry for pain processing in the dorsal horn. Nat Rev Neurosci 11: 823-836, 2010.

9. Kennedy PGE and Gershon AA: Clinical features of varicella-zoster virus infection. Viruses 10: 10, 2018.

10. Cunha C, Silva AJ, Pereira P, Vaz R, Gonçalves RM and Barbosa MA: The inflammatory response in the regression of lumbar disc herniation. Arthritis Res Ther 20: 251, 2018.

11. Wang JG, Strong JA, Xie W and Zhang JM: Local inflammation in rat dorsal root ganglion alters excitability and ion currents in small-diameter sensory neurons. Anesthesiology 107: 322-332, 2007.

12. Strong JA, Xie W, Coyle DE and Zhang JM: Microarray analysis of rat sensory ganglia after local inflammation implicates novel cytokines in pain. PLoS One 7: e40779, 2012.

13. Yu G, Wang LG, Han Y and He QY: clusterProfiler: An R package for comparing biological themes among gene clusters. OMICS 16: 284-287, 2012

14. Lin JS and Lai EM: Protein-protein interactions: Co-immunoprecipitation. Methods Mol Biol 1615: 211-219, 2017.

15. National Research Council (US): Committee for the Update of the Guide for the Care and Use of Laboratory Animals: Guide for the Care and Use of Laboratory Animals. 8th edition. National Academies Press, Washington, DC, 2011.

16. Xu F, Yang J, Lu F, Liu R, Zheng J, Zhang J, Cui W, Wang C, Zhou W, Wang Q, et al: Fast green FCF alleviates pain hypersensitivity and down-regulates the levels of spinal P2X4 expression and pro-inflammatory cytokines in a rodent inflammatory pain model. Front Pharmacol 9: 534, 2018.

17. Livak KJ and Schmittgen TD: Analysis of relative gene expression data using real-time quantitative PCR and the 2(-Delta Delta C(T)) method. Methods 25: 402-408, 2001.

18. Xie W, Strong JA, Kim D, Shahrestani S and Zhang JM: Bursting activity in myelinated sensory neurons plays a key role in pain behavior induced by localized inflammation of the rat sensory ganglion. Neuroscience 206: 212-223, 2012.

19. Oh SB, Tran PB, Gillard SE, Hurley RW, Hammond DL and Miller RJ: Chemokines and glycoprotein 120 produce pain hypersensitivity by directly exciting primary nociceptive neurons. J Neurosci 21: 5027-5035, 2001.

20. Li HL, Huang Y, Zhou YL, Teng RH, Zhou SZ, Lin JP, Yang Y, Zhu SM, Xu H and Yao YX: C-X-C motif chemokine 10 contributes to the development of neuropathic pain by increasing the permeability of the blood-spinal cord barrier. Front Immunol 11: 477, 2020.
21. Müller M, Carter S, Hofer MJ and Campbell IL: Review: The chemokine receptor CXCR3 and its ligands CXCL9, CXCL10 and CXCL11 in neuroimmunity - a tale of conflict and conundrum. Neuropathol Appl Neurobiol 36: 368-387, 2010.

22. Tokunaga R, Zhang W, Naseem M, Puccini A, Berger MD, Soni S, McSkane M, Baba H and Lenz HJ: CXCL9, CXCL10, CXCL11/CXCR3 axis for immune activation - A target for novel cancer therapy. Cancer Treat Rev 63: 40-47, 2018.

23. Sun RM, Wei J, Wang SS, Xu GY and Jiang GQ: Upregulation of IncRNA-NONRATT021203.2 in the dorsal root ganglion contributes to cancer-induced pain via CXCL9 in rats. Biochem Biophys Res Commun 524: 983-989, 2020.

24. Wu XB, He LN, Jiang BC, Shi H, Bai XQ, Zhang WW and Gao YJ: Spinal CXCL9 and CXCL11 are not involved in neuropathic pain despite an upregulation in the spinal cord following spinal nerve injury. Mol Pain: May 22, 2018.

25. Kawasaki Y, Xu ZZ, Wang X, Park JY, Zhuang ZY, Tan PH, Gao YJ, Roy K, Corfas G, Lo EH, et al: Distinct roles of matrix metalloproteases in the early- and late-phase development of neuropathic pain. Nat Med 14: 331-336, 2008.

26. Liou JT, Sum DC, Liu FC, Mao CC, Lai YS and Day YJ: Spatial and temporal analysis of nociception-related spinal cord matrix metalloproteinase expression in a murine neuropathic pain model. J Chin Med Assoc 76: 201-210, 2013.

27. Rojewska E, Popiolek-Barczyk K, Jurga AM, Makuch W, Przewlocka B and Mika J: Involvement of pro- and antinociceptive factors in minocycline analgesia in rat neuropathic pain model. J Neuroimmunol 277: 57-66, 2014.

28. Zhao L, Song C, Huang Y, Lei W and Sun J: MMP-9 regulates CX3CL1/CX3CR1 in the early phase of neuropathic pain in chronic sciatic nerve constriction injury (CCI) rats. Ann Palliat Med 9: 2020-2027, 2020.

29. Fritzinger DC and Benjamin DE: The complement system in neuropathic and postoperative pain. Open Pain J 9: 26-37, 2016.

30. Jang JH, Clark DJ, Li X, Yorek MS, Usachev YM and Brennan TJ: Nociceptive sensitization by complement $\mathrm{C} 5 \mathrm{a}$ and $\mathrm{C} 3 \mathrm{a}$ in mouse. Pain 148: 343-352, 2010.

31. Xu J, Zhang L, Xie M, Li Y, Huang P, Saunders TL, Fox DA, Rosenquist $\mathrm{R}$ and Lin F: Role of complement in a rat model of paclitaxel-induced peripheral neuropathy. J Immunol 200: 4094-4101, 2018.

32. Basbaum AI, Bautista DM, Scherrer G and Julius D: Cellular and molecular mechanisms of pain. Cell 139: 267-284, 2009.

33. Woolf CJ: Central sensitization: Implications for the diagnosis and treatment of pain. Pain 152 (Suppl 3): S2-S15, 2011.

34. Dawes JM, Calvo M, Perkins JR, Paterson KJ, Kiesewetter H, Hobbs C, Kaan TK, Orengo C, Bennett DL and McMahon SB: CXCL5 mediates UVB irradiation-induced pain. Sci Transl Med 3: 90ra60, 2011

35. Slade GD, Conrad MS, Diatchenko L, Rashid NU, Zhong S, Smith S, Rhodes J, Medvedev A, Makarov S, Maixner W, et al: Cytokine biomarkers and chronic pain: Association of genes, transcription, and circulating proteins with temporomandibular disorders and widespread palpation tenderness. Pain 152: 2802-2812, 2011

36. Padi SSV, Shi XQ, Zhao YQ, Ruff MR, Baichoo N, Pert CB and Zhang J: Attenuation of rodent neuropathic pain by an orally active peptide, RAP-103, which potently blocks CCR2and CCR5-mediated monocyte chemotaxis and inflammation. Pain 153: 95-106, 2012.

37. Liou JT, Lee CM and Day YJ: The immune aspect in neuropathic pain: Role of chemokines. Acta Anaesthesiol Taiwan 51: 127-132, 2013.

38. Matsushita K, Tozaki-Saitoh H, Kojima C, Masuda T, Tsuda M, Inoue $\mathrm{K}$ and Hoka $\mathrm{S}$ : Chemokine (C-C motif) receptor 5 is an important pathological regulator in the development and maintenance of neuropathic pain. Anesthesiology 120: 1491-1503, 2014.

39. Szabo I, Chen XH, Xin L, Adler MW, Howard OM, Oppenheim JJ and Rogers TJ: Heterologous desensitization of opioid receptors by chemokines inhibits chemotaxis and enhances the perception of pain. Proc Natl Acad Sci USA 99: 10276-10281, 2002.

40. Akgün E, Javed MI, Lunzer MM, Powers MD, Sham YY, Watanabe Y and Portoghese PS: Inhibition of inflammatory and neuropathic pain by targeting a Mu opioid receptor/chemokine receptor5 heteromer (MOR-CCR5). J Med Chem 58: 8647-8657, 2015.

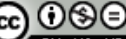

This work is licensed under a Creative Commons Attribution-NonCommercial-NoDerivatives 4.0 International (CC BY-NC-ND 4.0) License. 